Pacific Journal of Mathematics

A REMARK ON THE LEMMA OF GAUSS 


\section{A REMARK ON THE LEMMA OF GAUSS}

\section{FRED KRAKOWSKI}

Let $R$ be the ring of integers of some algebraic number field $K$ and $\mathfrak{P}=R\left[x_{0}, \cdots, x_{r}, y_{0}, \cdots, y_{s}\right]$, where the $x_{i}{ }^{\prime} s$ and $y_{j}{ }^{\prime} s$ are indeterminates. Call two ideals of $\mathfrak{B}$ equivalent, if after substitution of the indeterminates by arbitrary elements of $R$ they always yield identical ideals in $R$. For example, consider the ideal $I$ generated by the coefficients of the product of the two polynomials $f(t)=\sum_{i=0}^{r} x_{i} t^{i}$ and $g(t)=\sum_{j=0}^{s} y_{j} t^{j}$. According to the so-called Lemma of Gauss, $I$ is equivalent to the product $J$ of the ideals $\left(x_{0}, \cdots, x_{r}\right)$ and $\left(y_{0}, \cdots, y_{s}\right)$.

The object of this note is to show that the ideal $I$ has the following minimal property: It has the smallest number of generators, namely $r+s+1$, among all ideals in $\mathfrak{P}$ which are equivalent to $J$ in the above sense.

LEMMA 1. For every nonconstant polynomial $f \in R[t]$, $t$ an indeterminate, there exist infinitely many prime ideals $P \subset R$, such that the congruence $f(x) \equiv 0(\bmod P)$ has a solution $x \in R$.

Proof. Denote by $f_{1}, \cdots, f_{m}$ the polynomials conjugate to $f$ over the rationals and let $f=f_{1}$. Consider their product $F=f_{1} \cdots f_{m}$. The coefficients of $F$ are rational integers and thus there is an infinite sequence of rational primes $p_{1}, p_{2}, \cdots$ and corresponding rational integers $x_{1}, x_{2}, \cdots$, such that $F\left(x_{i}\right) \equiv 0\left(\bmod p_{i}\right), i=1,2, \cdots$ (see e.g. [1], p. 33).

Let now $L$ be a normal extension of the rationals containing $K$. For each $p_{i}$ choose a prime ideal $P_{i} \subset L$ containing $p_{i}$. Then $F\left(x_{i}\right) \equiv 0$ $\left(\bmod P_{i}\right)$. Since $\left(p_{i}, p_{j}\right)=(1)$ for $i \neq j$, we also have $P_{i} \neq P_{j}$. Thus there exist infinitely many prime ideals of $L$ which divide numbers of the sequence $F\left(x_{i}\right), i=1,2, \cdots$.

Assume now there exist only finitely many prime ideals in $R$, say $Q_{1}, \cdots, Q_{k}$, such that the congruence $f(x) \equiv 0\left(\bmod Q_{j}\right)$ has a solution in $R$ for $j=1, \cdots, k$. Denote by $Q_{1}^{\prime}, \cdots, Q_{k}^{\prime}$ the ideals in $L$ generated by $Q_{1}, \cdots, Q_{k}$. A prime ideal of $L$ containing $F\left(x_{i}\right)$ would then have to be also a divisor of some $Q_{j}^{\prime}$ or of an ideal conjugate to $Q_{j}^{\prime}$, because $F\left(x_{i}\right)$ is the product of the conjugate elements $f_{1}\left(x_{i}\right), \cdots, f_{m}\left(x_{i}\right)$. It would follow that there are only finitely many prime ideals of $L$ containing numbers of the sequence $F\left(x_{1}\right), F\left(x_{2}\right), \cdots$, which is a contradiction. This proves the lemma.

The next lemma gives a necessary condition which is satisfied by

Received June 2, 1964. The author is grateful to Professor Ernst Specker for many helpful conversations. 
equivalent ideals of a polynomial ring over $R$. Denote by $R^{n}$ the set of $n$-tuples of elements of $R$. If $t_{1}, \cdots, t_{n}$ are indeterminates and

$I=\left(f_{1}, \cdots, f_{r}\right) \subset R\left[t_{1}, \cdots, t_{n}\right], a \in R^{n}$, let $I_{a}=\left(f_{1}(a), \cdots, f_{r}(a)\right)$. Further let $C$ stand for the field of complex algebraic numbers, $C^{n}$ for the $n$-dimensional affine space over $C$ and $V_{I}$ for the algebraic variety in $C^{n}$ defined by the ideal $I$.

LEMmA 2. Let $I$ and $J$ be ideals of $R\left[t_{1}, \cdots, t_{n}\right]$ and suppose that for all $a \in R^{n}$ we have $I_{a}=J_{a}$. Then $V_{I}=V_{J}$.

Proof. Let $f_{1}, \cdots, f_{r}$ be a basis of $I$ and $g_{1}, \cdots, g_{s}$ a basis of $J$. Suppose $V_{I} \neq V_{J}$ and assume there is a point $\alpha=\left\langle\alpha_{1}, \cdots, \alpha_{n}\right\rangle$ of $V_{I}$ not contained in $V_{J}$. We must show that there exists a $n$-tuple $a \in R^{n}$, such that $I_{a} \neq J_{a}$.

Now $f_{i}(\alpha)=0, i=1, \cdots, r$ but, say, $g_{1}(\alpha) \neq 0 . \quad K\left(\alpha_{1}, \cdots, \alpha_{n}\right)$ is a separable algebraic extension of $K$, and let $\theta$ be a primitive element. We then have $\alpha_{i}=h_{i}(\theta), i=1, \cdots, n$, where $h_{i}$ is a polynomial whose coefficients may be assumed, without loss of generality, to be integers of $R$. Also let $p(t)$ be a polynomial in $R[t]$, of which $\theta$ is a root and which is irreducible in $K[t]$.

Put $F_{i}(t)=f_{i}\left(h_{1}(t), \cdots, h_{n}(t)\right), i=1, \cdots, r$ and $G_{1}(t)=g_{1}\left(h_{1}(t), \cdots, h_{n}(t)\right)$. Since $f_{i}(\alpha)=0, i=1, \cdots, r$ and $g_{1}(\alpha) \neq 0$, we have $F_{i}(\theta)=0, i=1, \cdots, r$ and $G_{1}(\theta) \neq 0$. Hence there are polynomials $q_{i}(t) \in R[t]$ and elements $s_{i} \in R, i=1, \cdots, r$, with $s_{i} F_{i}(t)=p(t) q_{i}(t), i=1, \cdots, r$. On the other hand, since $p(t)$ is irreducible and $G_{1}(\theta) \neq 0, p(t)$ and $G_{1}(t)$ are relatively prime in $K[t]$, and there are polynomials $A(t), B(t) \in R[t]$, such that

$$
A(t) p(t)+B(t) G_{1}(t)=c,
$$

where $c \in R$ and $c \neq 0$.

By Lemma 1 there are infinitely many prime ideals $P$ in $R$, such that the congruence $p(x) \equiv 0(\bmod P)$ has a solution in $R$. Each one of the numbers $s_{1}, \cdots, s_{r}$ and $c$ is contained in only a finite number of prime ideals. Hence there is a prime ideal $P \subset R$ and an element $x \in R$, such that $p(x) \equiv 0(\bmod P)$, but $s_{i} \neq \equiv 0(\bmod P), i=1, \cdots, r$ and $c \not \equiv 0(\bmod P)$. Therefore $B(x) G_{1}(x) \not \equiv 0(\bmod P)$. If we now let $a=\left\langle h_{1}(x), \cdots, h_{n}(x)\right\rangle$, then $a \in R^{n}$ and we get $g_{1}(a)=G_{1}(x) \not \equiv 0$ $(\bmod P)$ and thus also $J_{a} \not \equiv 0(\bmod P)$. On the other hand, since $s_{i} \notin P$, it follows that $F_{i}(x) \equiv 0(\bmod P)$, hence $f_{i}(a) \equiv 0(\bmod P), i=1, \cdots, r$ and thus $I_{a} \equiv 0(\bmod P)$. Therefore $I_{a} \neq J_{a}$, which was to be shown.

CoRollaRy. If for all $a \in R^{n}$ we have $I_{a}=(1)$, then $V_{I}=\phi$. 
Lemma 3. Consider polynomials $f_{1}, \cdots, f_{k} \in R[t]$. Assume that for all nonzero elements $r \in R$ the $k$ numbers $f_{1}(r), \cdots, f_{k}(r)$ generate the same ideal $I \subset R$. Then we also have $I=\left(f_{1}(0), \cdots, f_{k}(0)\right)$.

Proof. If $D$ is an ideal in $R, D \supset\left(f_{1}(0), \cdots, f_{k}(0)\right)$ and $r$ is an arbitrary nonzero element of $D$, then $\mathrm{f}_{i}(r) \in D$ for $i=1, \cdots, k$. Since $I=\left(f_{1}(r), \cdots, f_{k}(r)\right)$, we have $I \subset D$.

Conversely, if $D \supset I$ and $r \in D, r \neq 0$, then $f_{i}(r) \equiv f_{i}(0)(\bmod D)$. Since $f_{i}(r) \in D$, also $f_{i}(0) \in D$ for all $i$ and hence $\left(f_{1}(0), \cdots, f_{k}(0)\right) \subset D$. This proves the lemma.

Lemma 4. Let $f_{1}, \cdots, f_{k}$ be arbitrary and $g_{1}, \cdots, g_{m}$ homogeneous linear polynomials in $R\left[t_{1}, \cdots, t_{n}\right]$. Assume that for all $a \in R^{n}$ we have

$$
\left(f_{1}(a), \cdots, f_{k}(\alpha)\right)=\left(g_{1}(\alpha), \cdots, g_{m}(\alpha)\right) .
$$

Also denote by $h_{1}, \cdots, h_{k}$ the subpolynomials of $f_{1}, \cdots, f_{k}$ formed by their linear terms. Then $\left(h_{1}(a), \cdots, h_{k}(a)\right)=\left(g_{1}(a), \cdots, g_{m}(a)\right)$ for all $a \in R^{n}$.

Proof. Since $\left(g_{1}(0), \cdots, g_{m}(0)\right)=\left(f_{1}(0), \cdots, f_{k}(0)\right)=(0)$, we have $f_{1}(0)=\cdots=f_{k}(0)=0$. Thus $f_{i}=h_{i}+$ terms of degree $\geqq 2, i=$ $1, \cdots, k$. Take a fixed $n$-tuple $a \in R^{n}$ and let $r \in R$ be arbitrary but $\neq 0$. Then

$$
\begin{aligned}
\left(f_{1}(r a), \cdots, f_{k}(r a)\right) & =\left(r h_{1}(a)+r^{2}(\cdots), \cdots, r h_{k}(a)+r^{2}(\cdots)\right) \\
& =(r)\left(h_{1}(a)+r(\cdots), \cdots, h_{k}(a)+r(\cdots)\right) \\
& =\left(g_{1}(r a), \cdots, g_{m}(r a)\right)=(r)\left(g_{1}(a), \cdots, g_{m}(a)\right) .
\end{aligned}
$$

$R$ being an integral domain, we get

$$
\left(h_{1}(a)+r(\cdots), \cdots, h_{k}(a)+r(\cdots)\right)=\left(g_{1}(a), \cdots, g_{m}(a)\right)
$$

for all nonzero $r \in R$. By Lemma 2 therefore

$$
\left(h_{1}(a), \cdots, h_{k}(\alpha)\right)=\left(g_{1}(a), \cdots, g_{m}(a)\right),
$$

which was to be proved.

Theorem. Consider in $R\left[x_{0}, \cdots, x_{r}, y_{0}, \cdots, y_{s}\right]$ the ideal $J=$ $\left(x_{0}, \cdots, x_{r}\right)\left(y_{0}, \cdots, y_{s}\right)$ and suppose $I$ is an ideal such that for all $a \in R^{r+s+2}$ we have $I_{a}=J_{a}$. Then the number of elements in a basis of $I$ is at least $r+s+1$. 
Proof. Let $f_{1}, \cdots, f_{n}$ be a basis of $I$ and let $I^{\prime}$ be the ideal generated by the subpolynomials $b_{1}, \cdots, b_{n}$ of $f_{1}, \cdots, f_{n}$, which are linear with respect to $x_{0}, \cdots, x_{r}$ and with respect to $y_{0}, \cdots, y_{s}$. Since also the generators of $J$ are bilinear and for all $a \in R^{r+s+2}$ we have $I_{a}=J_{a}$, by Lemma 3 , we also have $I_{a}^{\prime}=J_{a}$ for all $a$.

Now the ideal $J$ has only trivial zeroes in $C^{r+s+2}$, either all $x_{i}=0$ or all $y_{j}=0$. On the other hand, if $n \leqq r+s$, it follows from a theorem of Macaulay (see [2], p. 54) that $I^{\prime}$ has a nontrivial zero in $C^{r+s+2}$. By Lemma 2 this cannot happen. Hence $n \geqq r+s+1$.

\section{REFERENCES}

1. A. Scholz, Einführung in die Zahlentheorie, Sammlung Göschen Band 1131, Berlin 1939.

2. F.S. Macaulay, Algebraic Theory of Modular Systems, Cambridge Tracts in Math. 19, Cambridge 1916.

University of CALIFornia, Davis 


\section{PACIFIC JOURNAL OF MATHEMATICS}

\section{EDITORS}

\author{
H. Samelson \\ Stanford University \\ Stanford, California \\ R. M. Blumenthal \\ University of Washington \\ Seattle, Washington 98105
}

\author{
J. Dugundu \\ University of Southern California \\ Los Angeles, California 90007 \\ *Richard Arens \\ University of California \\ Los Angeles, California 90024
}

\section{ASSOCIATE EDITORS}
E. F. BeCKENBACH
B. H. NeUMANN
F. WOLF
K. YosidA

\section{SUPPORTING INSTITUTIONS}

\author{
UNIVERSITY OF BRITISH COLUMBIA \\ CALIFORNIA INSTITUTE OF TECHNOLOGY \\ UNIVERSITY OF CALIFORNIA \\ MONTANA STATE UNIVERSITY \\ UNIVERSITY OF NEVADA \\ NEW MEXICO STATE UNIVERSITY \\ OREGON STATE UNIVERSITY \\ UNIVERSITY OF OREGON \\ OSAKA UNIVERSITY \\ UNIVERSITY OF SOUTHERN CALIFORNIA
}

\author{
STANFORD UNIVERSITY \\ UNIVERSITY OF TOKYO \\ UNIVERSITY OF UTAH \\ WASHINGTON STATE UNIVERSITY \\ UNIVERSITY OF WASHINGTON \\ * * * * \\ AMERICAN MATHEMATICAL SOCIETY \\ CALIFORNIA RESEARCH CORPORATION \\ SPACE TECHNOLOGY LABORATORIES \\ NAVAL ORDNANCE TEST STATION
}

Mathematical papers intended for publication in the Pacific Journal of Mathematics should by typewritten (double spaced). The first paragraph or two must be capable of being used separately as a synopsis of the entire paper. It should not contain references to the bibliography. No separate author's resumé is required. Manuscripts may be sent to any one of the four editors. All other communications to the editors should be addressed to the managing editor, Richard Arens, at the University of California, Los Angeles, California 90024.

50 reprints per author of each article are furnished free of charge; additional copies may be obtained at cost in multiples of 50 .

The Pacific Journal of Mathematics is published quarterly, in March, June, September, and December. Effective with Volume 13 the price per volume (4 numbers) is $\$ 18.00$; single issues, $\$ 5.00$. Special price for current issues to individual faculty members of supporting institutions and to individual members of the American Mathematical Society: $\$ 8.00$ per volume; single issues $\$ 2.50$. Back numbers are available.

Subscriptions, orders for back numbers, and changes of address should be sent to Pacific Journal of Mathematics, 103 Highland Boulevard, Berkeley 8, California.

Printed at Kokusai Bunken Insatsusha (International Academic Printing Co., Ltd.), No. 6, 2-chome, Fujimi-cho, Chiyoda-ku, Tokyo, Japan.

PUBLISHED BY PACIFIC JOURNAL OF MATHEMATICS, A NON-PROFIT CORPORATION

The Supporting Institutions listed above contribute to the cost of publication of this Journal, but they are not owners or publishers and have no responsibility for its content or policies.

* Basil Gordon, Acting Managing Editor until February 1, 1966. 


\section{Pacific Journal of Mathematics}

\section{Vol. 15, No. $3 \quad$ November, 1965}

David R. Arterburn and Robert James Whitley, Projections in the space of

bounded linear operators .................................

Robert McCallum Blumenthal, Joram Lindenstrauss and Robert Ralph Phelps,

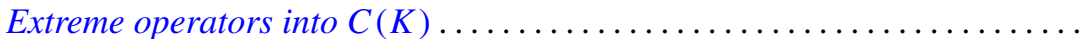

L. Carlitz, A note on multiple exponential sums ................... 757

Joseph A. Cima, A nonnormal Blaschke-quotient .................... 767

Paul Civin and Bertram Yood, Lie and Jordan structures in Banach algebras . . . 775

Luther Elic Claborn, Dedekind domains: Overrings and semi-prime

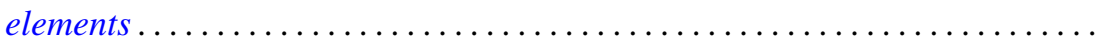

799

Luther Elic Claborn, Note generalizing a result of Samuel's .............. 805

George Bernard Dantzig, E. Eisenberg and Richard Warren Cottle, Symmetric

dual nonlinear programs ................................... 809

Philip J. Davis, Simple quadratures in the complex plane ............... 813

Edward Richard Fadell, On a coincidence theorem of F. B. Fuller ............ 825

Delbert Ray Fulkerson and Oliver Gross, Incidence matrices and interval

graphs ........................................ 835

Larry Charles Grove, Tensor products over $H^{*}$-algebras ..................

Deborah Tepper Haimo, $L^{2}$ expansions in terms of generalized heat polynomials

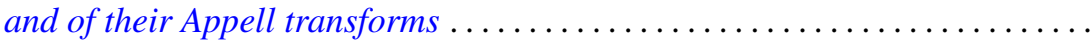

I. Martin (Irving) Isaacs and Donald Steven Passman, A chardcterization of groups in terms of the degrees of their characters ..........

Donald Gordon James, Integral invariants for vectors over local fields........ 905

Fred Krakowski, A remark on the lemma of Gauss ................... 917

Marvin David Marcus and H. Minc, A subdeterminant inequality ........... 921

Kevin Mor McCrimmon, Norms and noncommutative Jordan algebras ........ 925

Donald Earl Myers, Topologies for Laplace transform spaces ............... 957

Olav Njstad, On some classes of nearly open sets .................... 961

Milton Philip Olson, A characterization of conditional probability ........... 971

Barbara Osofsky, A counter-example to a lemma of Skornjakov .............. 985

Sidney Charles Port, Ratio limit theorems for Markov chains ............... 989

George A. Reid, A generalisation of $W^{*}$-algebras ...................... 1019

Robert Wells Ritchie, Classes of recursive functions based on Ackermann's

function ........................................... 1027

Thomas Lawrence Sherman, Properties of solutions of $n$th order linear

differential equations ........................................ 1045

Ernst Snapper, Inflation and deflation for all dimensions . .............. 1061

Kondagunta Sundaresan, On the strict and uniform convexity of certain Banach

spaces............................................. 1083

Frank J. Wagner, Maximal convex filters in a locally convex space .......... 1087

Joseph Albert Wolf, Translation-invariant function algebras on compact 